\title{
Other journals in brief
}

\section{'MOST PROFESSIONAL'}

No need for wist (women in suits and ties): patient views on work wear for the female surgeon

Gutierrez T, Pilgrim G et al. Ann R Coll Surg Engl (Supp/) 2011; 93: 274-277

Demise of the white coat?

The authors cite others who suggest, possibly with vexation, that the wearing of white coats was abolished not to reduce nosocomial infection rates, but so that patients cannot differentiate between doctors and other healthcare workers. But what do patients think of that much maligned white coat? Sixty-six patients looked at pictures of three women surgeons wearing four different uniforms/clothes. A questionnaire was then answered on how that dress reflected specific issues. When wearing white coats, patients considered that the surgeons appeared 'most professional' and 'trustworthy'. Those who wore suits, were judged to be in a position of authority although this dress does not comply with the 'bare below the elbows' mantra. Surgical scrubs were viewed as most hygienic. When asked what was the occupation of those who wore the different uniforms/clothes, one response was that the wearers (attire not stated) were air cabin crew! DOI: 10.1038/sj.bdj.2011.1075

\section{LINKING DENTAL AND SYSTEMIC INFECTION}

\section{Brain abscess associated with Aggregatibacter actinomycetemcomitans: case report and review of literature}

Rahamat-Langendoen JC, van Vonderen MGA et al. J Clin Periodonto/ 2011; 38: 702-706

An association between the oral bacterial species Aggregatibacter actinomycetemcomitans and systemic infection.

This case report describes a 42-year-old hospitalised patient with multiple brain abscesses. There was no underlying medical condition. Conventional microbiological culture was negative although subsequent $16 \mathrm{~S}$ rDNA polymerase chain reaction (gene amplification) and sequence analysis showed that Aggregatibacter actinomycetemcomitans was the causative agent. Treatment consisted of repeated drainage of the brain abscesses and antimicrobial therapy and subsequent extraction of hopeless teeth. The authors stated that the antimicrobial regimen was somewhat empirical. Nevertheless, it included ceftriaxone, a third generation cephalosporin, for which A. actinomycetemcomitans is susceptible. As no other focus of infection could be found, the patient's poor dental health was considered the source.

DOI: 10.1038/sj.bdj.2011.1076

\section{ORTHOGNATHIC SURGERY}

Effects of orthognathic surgery on oropharyngeal airway: a meta-analysis

Mattos CT, Vilani GNL et al. Int J Oral Maxillofac Surg 2011; doi:10.1016/j.ijom.2011.06.020

\section{Pharyngeal dimensional changes.}

Does orthognathic surgery cause obstructive sleep apnoea? Although not exploring this question, this meta-analysis looked at pharyngeal dimensional changes following orthognathic surgery. Such changes are a putative co-morbidity factor for obstructive sleep apnoea. The data from 13 studies were pooled for this meta-analysis. There is moderate evidence that there is a "significant decrease in the oropharyngeal airway in mandibular setback surgery (and), a milder decrease in bimaxillary surgery to correct Class III'. Not only have pharyngeal dimensional changes associated with orthognathic surgery been explored, but recently investigators have looked for such changes after orthodontic treatment. In adult orthodontic patients with bimaxillary protrusion, it has been reported that 'pharyngeal airway size became narrower' following extraction of four premolar teeth and retraction of incisors.

DOI: 10.1038/sj.bdj.2011.1077

\section{PROFESSIONALISM}

\section{Maintaining surgical professionalism \\ Taylor I. Ann R Coll Surg Engl (Suppl) 2011; 93: 270-273}

'a set of values, behaviours and relationships that underpins the trust of the public...'

There is a perception that professionalism is being eroded by a 'target-driven delivery of healthcare'. Yet within this backdrop with an ever increasing emphasis on neoliberalism, if there are treatment errors then 'to cover up is unforgivable and to fail to learn is inexcusable.' At the heart of professionalism is effective patient care, but there are also non-clinical attributes. The author argues that poor meeting discipline or playing one colleague off against another are examples of lapses in professionalism. The National Clinical Assessment Service has identified myths in remediating such behaviour such as hoping it will go away or, as they assert, trying to facilitate such tensions internally. Yet the author argues the reluctance of healthcare trusts to investigate locally may be a cause for an increase of referrals to the Regulatory Bodies.

DOI: 10.1038/sj.bdj.2011.1078 